\title{
Mechanism of stratospheric decadal abrupt cooling in the Early 1990s as influenced by the Pinatubo eruption
}

\author{
XIAO Dong ${ }^{1} \&$ LI JianPing ${ }^{2 *}$ \\ ${ }^{1}$ Chinese Academy of Meteorological Sciences, Beijing 100081, China; \\ ${ }^{2}$ National Key Laboratory of Numerical Modeling for Atmospheric Sciences and Geophysical Fluid Dynamics, Institute of Atmospheric Physics, \\ Chinese Academy of Sciences, Beijing 100029, China
}

Received August 24, 2010; accepted November 16, 2010

\begin{abstract}
Studies have suggested that one volcanic eruption can influence seasonal to inter-annual climate variations. This study indicates that the Pinatubo eruption in 1991 may have actually induced the stratospheric decadal cooling recorded in the early 1990s. Using the NCEP/NCAR reanalysis and TOMS/SBUV satellite data, a decadal abrupt cooling of stratospheric tropical air temperature was found to have occurred in the early 1990s during a long-term descending trend. We generated the spatio-temporal structures of the decadal abrupt changes (DACs) for the stratosphere, and explored the relationship between the Pinatubo volcano eruption in 1991 and stratospheric DACs in the early 1990s. Our results suggest that the eruption of Pinatubo prompted a decadal decrease of ozone by the activation of nitrate and sulfate volcanic aerosols on $\mathrm{ClO}$ free radicals. The stratospheric heat absorbed by ozone decreased over a decadal time scale. As a result, decadal abrupt cooling of stratospheric tropical air temperatures occurred in the early 1990s, and may be attributed to the Pinatubo eruption. The results therefore indicate that one strong volcanic eruption can induce stratospheric decadal climate variation.
\end{abstract}

Pinatubo, volcanic eruption, stratosphere, decadal abrupt cooling, ozone

Citation: Xiao D, Li J P. Mechanism of stratospheric decadal abrupt cooling in the Early 1990s as influenced by the Pinatubo eruption. Chinese Sci Bull, 2011, 56: 772-780, doi: $10.1007 / \mathrm{s} 11434-010-4287-9$

Volcano-climatology is a new interdisciplinary field, which provides important theoretical and practical information [1]. Volcanic activity, together with solar activity and greenhouse gases, is an important external forcing of climate change. It has been observed that strong volcanic eruptions can have environmental influences within large spatial scales (i.e. global climate change) and large temporal scales (i.e., seasonal to geological scales), via volcanic aerosols erupted into the stratosphere. The influence of volcanic activities may be greater than that of solar activity and greenhouse gas effects [1-3]. To adequately evaluate the relative contribution of anthropogenic and natural forcings on 20th century warming effects, it is necessary to consider the contribution of natural forcings, such as volcanic and solar activities. Volcanic activity is an important interface between

*Corresponding author (email: ljp@lasg.iap.ac.cn) the Earth's interior and outer spheres. Thus, volcano-climology processes play an important role in global climate change.

The impact of volcanic activity on climate change may have long-term effects on the planet. However, one volcanic eruption cannot determine climatic variability across all time-scales. At seasonal to inter-annual time scales, one strong volcanic eruption could induce stratospheric warming and tropospheric cooling. Within century to geologic time scales, the continuous effects of many volcanic eruptions may lead to long-term cooling trends. Hence, the effects on decadal climatic variability have been attributed to the continuous effects of ongoing volcanic eruptions over long time scales. It is unclear as to whether one volcanic eruption could induce decadal climate variability. However, if it could, this would mean that the impacts of one strong volcanic eruption could be maintained through a series of 
decadal time scales. Such volcanic impacts are important for climate change.

At present, there are still many active volcanoes all over the world. For example, the Tianchi volcano at Changbai Mountain may become active in the future. It has been suggested that its destructive power could be stronger than that of the Pinatubo eruption in 1991, which was the strongest eruption in the last century. This situation thus could resemble that of the catastrophic effects of the Tambora eruption in 1815 and Pinatubo eruption in 1991. Thus, it is necessary to quantitatively investigate the potential influences of one significant volcanic eruption on long-term climate changes.

The Pinatubo volcano at Luzon Island, Philippines, erupted on 12th-16th June 1991. This eruption was identified as a 6th level within the Volcanic Explosivity Index (VEI) by the standards of the Smithsonian Institute [4]. The 1991 eruption of Pinatubo was the largest volcanic eruption in the 20th century, and produced about 5 cubic kilometers of volcanic ash. Eruption columns reached 40 kilometers in altitude and emplaced a giant umbrella cloud in the middle to lower stratosphere. According to satellite surveys [5], volcanic aerosols spread rapidly around the Earth in about 3 weeks and attained global coverage in about 1 year after the eruption. The zonal mean mid-visible optical depths were about 0.1 for two years, twice as much as that in non-volcano years [6]. The Pinatubo volcanic ash also was found in the South Polar region [7]. El Chichon and Pinatubo volcanic eruptions may have played an important part in the decrease of the total column zone over Beijing [8]. As a result, the optical depth over Beijing at a $0.7 \mu \mathrm{m}$ wavelength was larger than 0.1 until April 1992 [9]. Enhancement of column optical depth and a decrease of clear sky short wave direct radiation reached $0.041-0.295$ and $6 \%$ to $35 \%$ over Beijing and nine other Chinese cities [10].

The Pinatubo volcanic eruption had great impacts not only on global radiation, but also on stratospheric chemical processes. Observations following the eruption displayed significant reductions in $\mathrm{NO}_{2}[11,12]$ and increased concentrations of $\mathrm{HNO}_{3}$ [13]. These changes indicate that reactive nitrogen species were repartitioned into less reactive forms which, in turn, helped to temporarily enhance the levels of active, ozone-depleting chlorine radicals relative to those of the more inert chlorine reservoirs. Observations at that time showed evidence of greater ozone depletion than that expected in response to the normal increase in stratospheric chlorine amounts $[14,15]$. Moreover, the rate of atmospheric methane increase slowed dramatically after the eruption within a decadal time scale [16,17].

Significant warming of stratospheric air temperature occurred during the subsequent 2-4 months after the Pinatubo eruption, and cooling of the troposphere occurred after 10 months [2]. The effects on climate presented an observed surface cooling in the Northern Hemisphere of up to 0.5 to $0.6^{\circ} \mathrm{C}$. The reduction in tropospheric air temperature was accompanied by the reduction of stratospheric optical depth until 1994-1995. Stratospheric global air temperature in 1992 was the warmest since after the El Chichon eruption, which contributed to heating of high temperature volcanic ash and heating of volcanic aerosol clouds via absorption of the upward long wave radiation from the surface. However, 30-hPa global geopotential height (Figure 1(a)) and air temperature (Figure 1(b)) have decreased sharply since 1993, and have moved into a new stable state of mean values. The mean value of $30-\mathrm{hPa}$ global air temperature in the period 1952-1992 was $1.26^{\circ} \mathrm{C}$ greater than that in the period between 1993 to 2009, which was calculated with a $99.9 \%$ confidence level. Thus, this change represents a dramatic decadal cooling event. It is important to understand the spatio-temporal structures of the stratospheric decadal cooling event, and the global or regional cover of this event. It also is critical to determine if the event had effects only at 30 $\mathrm{hPa}$ or also in the stratosphere. Further research may elucidate whether there is a direct relationship between the early 1990s decadal cooling event and the Pinatubo volcanic eruption. If there is such a relationship, it is also important to determine the relevant physical and chemical processes involved. With these questions in mind, this paper investigates the horizontal and vertical characteristics of stratospheric decadal abrupt change (DAC). Furthermore, we discuss the influences of the Pinatubo eruption on the total column ozone and the early 1990s stratospheric DAC, and we explore the physical and chemical processes involved in this relationship.

\section{Data and methods}

In this study, we used annual averaged data, which were derived from monthly datasets as follows. Monthly mean

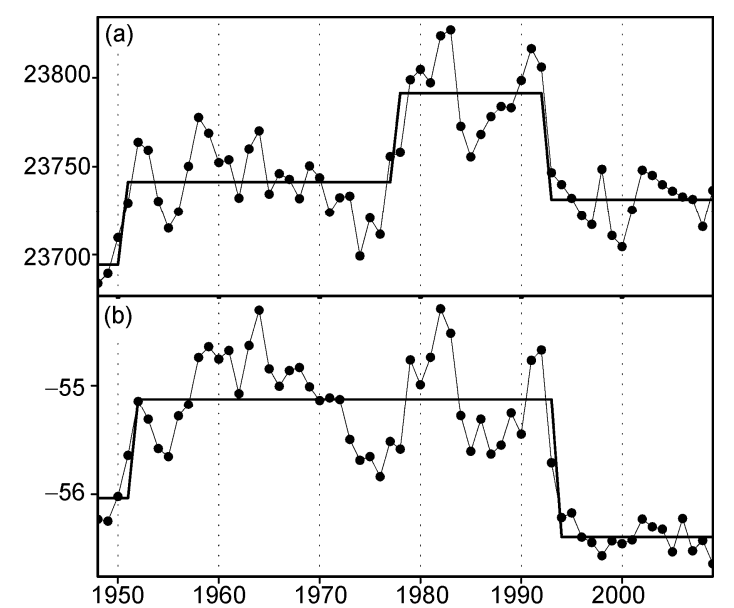

Figure 1 Time series and epoch average of (a) 30-hPa global geopotential height (Unit: geopotential meter, gpm) and (b) global air temperature (Unit: ${ }^{\circ} \mathrm{C}$ ). The epoch averages are divided by the DAC years (DACYs) significant at the $99.9 \%$ confidence levels. 
geopotential heights and air temperatures were obtained from the National Centers for Environmental Prediction/ National Center for Atmosphere Research (NCEP/NCAR) reanalysis datasets (Jan. 1948-Feb. 2010) on $2.5^{\circ} \times 2.5^{\circ}$ latitude/longitude grids [18]. The monthly TOMS/SBUV total column ozone (Nov. 1978-Jul. 2006) (Version 8) was obtained from the Goddard Space Flight Center (GSFC) with a resolution of $10^{\circ} \times 5^{\circ}$ latitude/longitude grids.

This study focused on decadal climate variability, the concepts of which are introduced here. Decadal climate variability is the climatic variability within decade-to-entury time scales that is restricted by the time scales, but not by variational styles. Decadal climate variability may be divided into three types of variational styles [19-21]. First, the period variation contains the decadal time scale period. Second, the abrupt change stands for the rapid transition for one stable state to another. Under the different definitions for a stable state, abrupt change may be divided into abrupt change of mean value, variance, trend and probability. Third, the gradual variation or decadal trend of climate variability indicates the slow transition between two stable states.

The mean value of the stratospheric tropical 30-hPa air temperature declined suddenly in the early1990s. Thus, it is necessary to employ a method for detecting abrupt change of mean value to detect the DAC years (DACYs) of this stratospheric cooling. Feng et al. [22] applied a physical method to detect the nonlinear dynamic abrupt changes of the climate system. Xiao and Li [21] compared the detecting methods of abrupt change of mean values and explained the applied mistakes of the moving $t$-test technique (MTT). MTT may be used to examine several DACYs in a time series with a certain time scale. Xiao and Li [23] reinforced the MTT with tests of the normal distribution, correction of effective free degrees and correction of false discovery rates. This paper focuses on decadal abrupt changes of mean values (DACMV, hereafter referred to as DAC for simplicity). We take the detecting scales $n_{1}=n_{2}=10$ as a decadal time scale. The DACY represents the transition year between two different stable states of mean values, which signifies that the difference between the stable states before and after the DACY are significant at the $95 \%$ confidence level. A more detailed depiction of the MTT is described in the study by Xiao and Li [23].

\section{Spatio-temporal characteristics of stratospheric DACs}

The MTT was used to detect the DACYs in the time series on every grid of 30-hPa air temperature field. The horizontal distribution of the DACYs of 30-hPa air temperature was obtained by overlapping the temporal cross-section of DACYs in the early 1990s. It can be seen from Figure 2(a) that the decreased DACs (DDACs, the variable decreases after the DACY) occurred over the subtropical North Atlantic in 1991, over the tropics in 1992, over the northern and southern subtropics in 1993, and over the mid-latitudes in 1994-1995. The DDACs of 30-hPa geopotential height took place over the tropics in 1993-1995 (Figure 2(b)). The
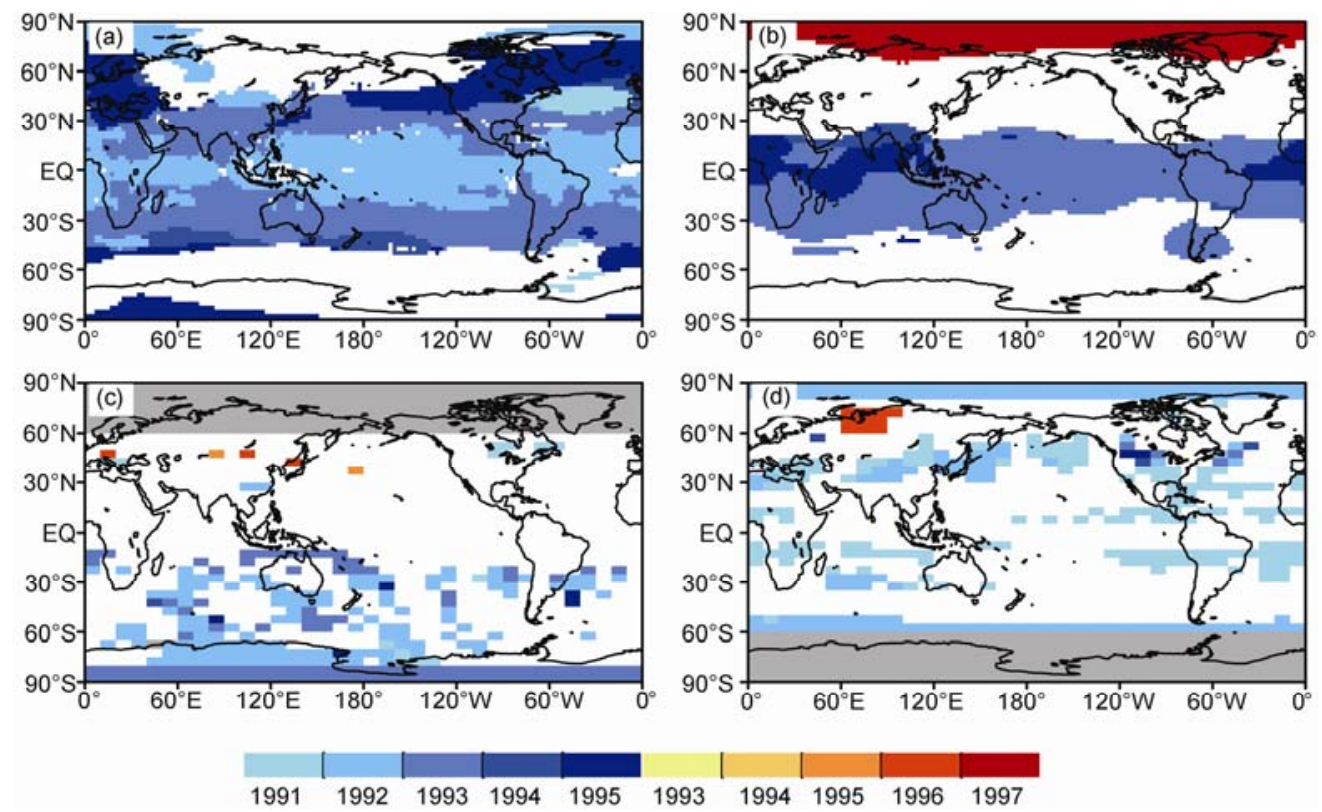

Figure 2 Horizontal distributions of the DACYs in 1990s of annual averaged fields of (a) 30-hPa air temperature, (b) 30-hPa geopotential height, (c) January total column ozone, (d) July total column ozone. The cold color system (e.g. blue) and warm color system (e.g. yellow, red) represent the decreased DACYs and increased DACYs significant at 0.05 confidence level, respectively. The false discovery rates of the DACYs in each field are controlled at 0.05 . The grey shading denotes the missing regions of total column ozone. 
increased DAC (IDAC, the variable increases after the DACY) occurred over the Arctic in 1997. The Arctic IDAC, which was located across the stratosphere and troposphere, represented equivalent barotropic structures. The Arctic IDAC occurred later than the tropical DDACs. These facts suggest that the Arctic IDAC and tropical DDACs do not belong to one DAC event. We will discuss the Arctic IDAC of 1997 in a future paper. It can be observed that the January DDACs of total column ozone occurred over the southern hemisphere in 1992-1993 (Figure 2(c)), and the July DDACs of total column ozone took place over the southern and northern subtropical, Arctic and southern subpolar areas in 1992-1993 (Figure 2(d)). Hence, the DDACs of total column ozone occurred later than the Pinatubo eruption of June 1991.

The MTT was used to detect DACs in the time series of the tropical geopotential heights and air temperatures at all levels. Accordingly, the vertical distribution of tropical geopotential height could be displayed. The DDACs of tropical geopotential height occurred at $70-10 \mathrm{hPa}$ in 1993-1997 (Figure 3(a)). In the height-time cross-section of the tropical geopotential height (Figure 3(c)), a sudden decadal decrease could be found above the $50-\mathrm{hPa}$ level. The DDACs of tropical air temperatures took place at 100-20 hPa in 1992-1997 (Figure 3(b)). The height-time cross-section of tropical air temperatures indicated that the decadal cooling mainly occurred in the middle stratosphere (50-20 hPa).
The tropical cooling includes three episodes as follows (Figure 3(d)). First, the positive air temperature anomalies changed to negative anomalies since the mid 1960s. Second, the negative anomalies of about -1 to $-0.5^{\circ} \mathrm{C}$ transformed to about -1.5 to $-1^{\circ} \mathrm{C}$ since the early 1980 s. Third, the negative air temperature anomalies changed to be the greatest among all the data periods, at about -2.5 to $-1.5^{\circ} \mathrm{C}$. Thus, the occurrence time of the decadal variation of stratospheric tropical air temperature was in the mid 1960s, early 1980s and early 1990s, respectively. In the second half of the 20th century, there were three strong volcanic eruptions with VEIs equal to or greater than the 4th level. These eruptions included the Pinatubo eruption in the Philippines $\left(120^{\circ} \mathrm{E}, 15^{\circ} \mathrm{N}\right)$ in June of 1991 , the El Chichon eruption in Mexico $\left(93^{\circ} \mathrm{W}, 17^{\circ} \mathrm{N}\right)$ on April 1982, and the Agung eruption in Indonesia $\left(116^{\circ} \mathrm{E}, 8^{\circ} \mathrm{S}\right)$ in March 1963 . The VEI of the above eruptions were the 6th, 5th and 4th levels, respectively. It was found that the occurrence time of the stratospheric decadal variation coincided with that of the tropical strong eruptions.

To confirm the authenticity of the DACs in the 1990s, several time series are shown in Figure 4, which were selected according to the DAC regions in Figure 2. The IDACs of the tropical 30-hPa geopotential height occurred in 1977, and the DDACs of the tropical 30-hPa geopotential height took place in 1964 and 1993 (Figure 4(a)). The mean
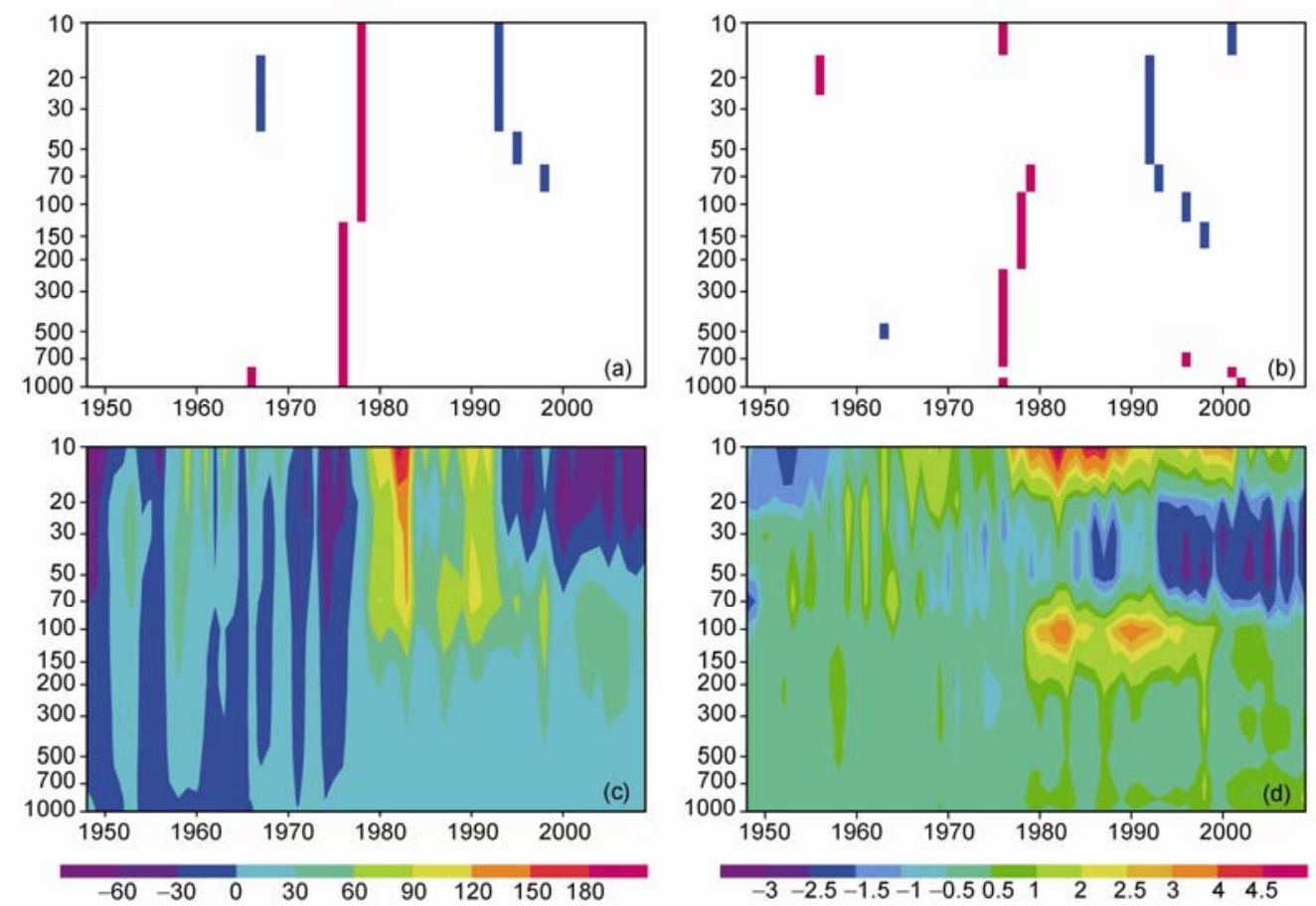

Figure 3 Vertical distributions of DACYs of annual averaged (a) geopotential height over $\left(0^{\circ}-357.5^{\circ} \mathrm{E}, 20^{\circ} \mathrm{S}-20^{\circ} \mathrm{N}\right),(\mathrm{b})$ air temperature over $\left(0^{\circ}-357.5^{\circ} \mathrm{E}\right.$, $\left.15^{\circ} \mathrm{S}-15^{\circ} \mathrm{N}\right)$. The red and blue colors indicate the increased DACYs and decreased DACYs, respectively, which exceed the 0.05 significant confidence level. The false discovery rates of the DACYs in each field were controlled at 0.05 . Height-time cross-sections of departures of (c) geopotential height over $\left(0^{\circ}-357.5^{\circ} \mathrm{E}, 20^{\circ} \mathrm{S}-20^{\circ} \mathrm{N}\right)$ (Unit: gpm) and (d) air temperature over $\left(0^{\circ}-357.5^{\circ} \mathrm{E}, 15^{\circ} \mathrm{S}-15^{\circ} \mathrm{N}\right)$ (Unit: $\left.{ }^{\circ} \mathrm{C}\right)$. The anomalies are relative to the mean values of the period 1948-1977. 
value of the tropical 30-hPa geopotential height after 1993 was 76.8 (geopotential meter, gpm) lower than that of 1978-1992. Besides the DAC in 1964, the DACs in 1977 and 1993 of the tropical 30-hPa geopotential height coincided with that of the global 30-hPa geopotential height. The DDACs of the tropical 30-hPa air temperature occurred in 1966, 1983 and 1992 (Figure 4(b)). The stratospheric air temperature moved into a stable state after the DAC in 1992. The mean value after 1992 was $1.1^{\circ} \mathrm{C}$ lower than that before 1992. The DACs of tropical 30-hPa air temperature took place in 1966, 1977 and 1992. However, that of the global 30-hPa air temperature took place only in 1992. Thus, study of decadal variability should emphasize regional characteristics. The DDACs of the January total column ozone occurred in 1983 and 1992 (Figure 4(c)) with a decrease of 9.5 and 7 Dobson Units (DU) of mean values, respectively. The DDACs of the July total column ozone occurred in 1991, with a decrease of $7.89 \mathrm{DU}$ of mean value (Figure 4(d)). According to the occurrence time, the DDACs of the January and July total column ozone took place just after the Pinatubo eruption on June 1991.

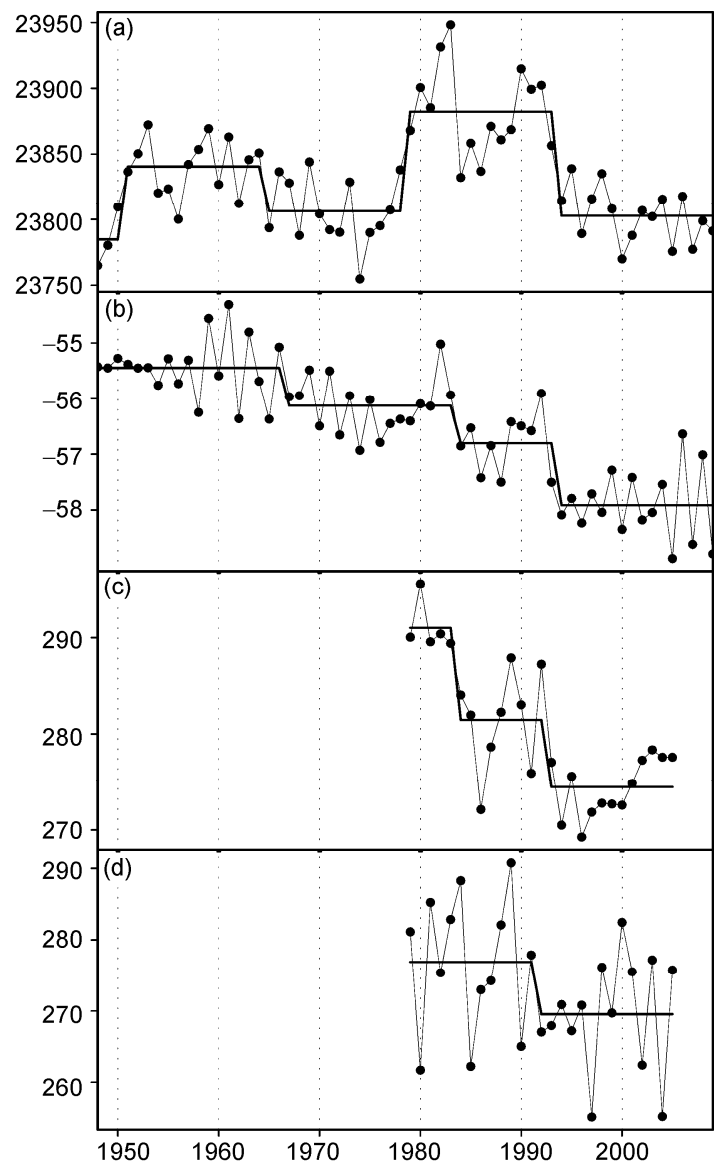

Figure 4 Same as Figure 1, but for (a) 30-hPa geopotential height over $\left(0^{\circ}-357.5^{\circ} \mathrm{E}, 20^{\circ} \mathrm{S}-20^{\circ} \mathrm{N}\right)$, (b) $30-\mathrm{hPa}$ air temperature over $\left(0^{\circ}-357.5^{\circ} \mathrm{E}\right.$, $\left.15^{\circ} \mathrm{S}-15^{\circ} \mathrm{N}\right)$, (c) January total column ozone over $\left(40^{\circ} \mathrm{E}-120^{\circ} \mathrm{W}, 80^{\circ}-20^{\circ} \mathrm{S}\right)$ (Unit: DU) and (d) July total column ozone over $\left(120^{\circ} \mathrm{E}-120^{\circ} \mathrm{W}, 30^{\circ}-20^{\circ} \mathrm{S}\right)$ (Unit: DU). The DACYs detected by MTT all exceed the 0.05 significant confidence levels.
According to the spatio-temporal distribution of the stratospheric DACs, those of the early 1990s are typified by large coverage and systemic cooling in the stratosphere. As has been noted, the Pinatubo eruption started on June 1991. Subsequently, July and January total column ozone decreased since 1991 and 1992, respectively. Furthermore, the stratospheric air temperature decreased since 1992, which was synchronous with or lagged the DDACs of total column ozone. It is unclear as to whether the order among the Pinatubo eruption, decadal ozone depletion and stratospheric decadal cooling indicate a chemical and/or physical relationship.

\section{Relationship between the Pinatubo eruption and stratospheric DDACs}

\subsection{Instance of Pinatubo eruption}

Based on the relationship between the Pinatubo eruption and ozone decadal depletion and stratospheric decadal cooling, and to better understand chemical processes in the stratosphere, it is necessary to analyze the Pinatubo eruption and the chemical components of volcanic ash. On 12-16 June, 1991, the Pinatubo eruption produced about 5 cubic kilometers of dacitic magma. Eruption columns reached 40 kilometers in altitude and emplaced a giant umbrella cloud in the middle to lower stratosphere that injected about 17 megatons of $\mathrm{SO}_{2}, 3$ megatons of $\mathrm{Cl}, 42$ megatons of $\mathrm{CO}_{2}$, 491 megatons of $\mathrm{H}_{2} \mathrm{O}$ and many other gases [5]. It can be seen from Figure 5 that the stratospheric optical depths had a magnitude of $10^{-3}$ before the Pinatubo eruption (Figure 5, upper left). The minimal region of optical depth was over the northern subtropics. The aerosol cloud spread rapidly (in about 3 weeks) around the Earth (Figure 5, upper right), and achieved global coverage for about 1 year after the eruption [24]. Peak local mid-visible optical depths of up to 0.4 were measured in late 1992, and global averaged values were about 0.1 to 0.15 for about 2 years [24] (Figure 5, lower right).

The volcanic ash spread to the tropics in 1991 along the equatorial easterlies, and attained global coverage in 1992. Similarly, the tropical DDAC occurred in 1992, the subtropical DDAC in 1993, and the mid-latitude DDACs in 1994-1995. Hence, this temporal order of volcanic ash spread was similar to that of the occurrence time of the stratospheric DDACs. Moreover, the volcanic ash coverage arrived one year before the stratospheric DDACs.

Stratospheric warming in 1991-1992 was caused by heating of volcanic ash, which was thrown up into the stratosphere. More importantly, the stratospheric atmosphere was heated by the surface long wave radiation absorbed by the volcanic ash cloud. Tropospheric cooling in 1992 was attributed to dramatic decreases in the amount of net radiation reaching the Earth's surface, which was dispersed and refracted by volcanic ash via the "Umbrella Effect" [2]. The 

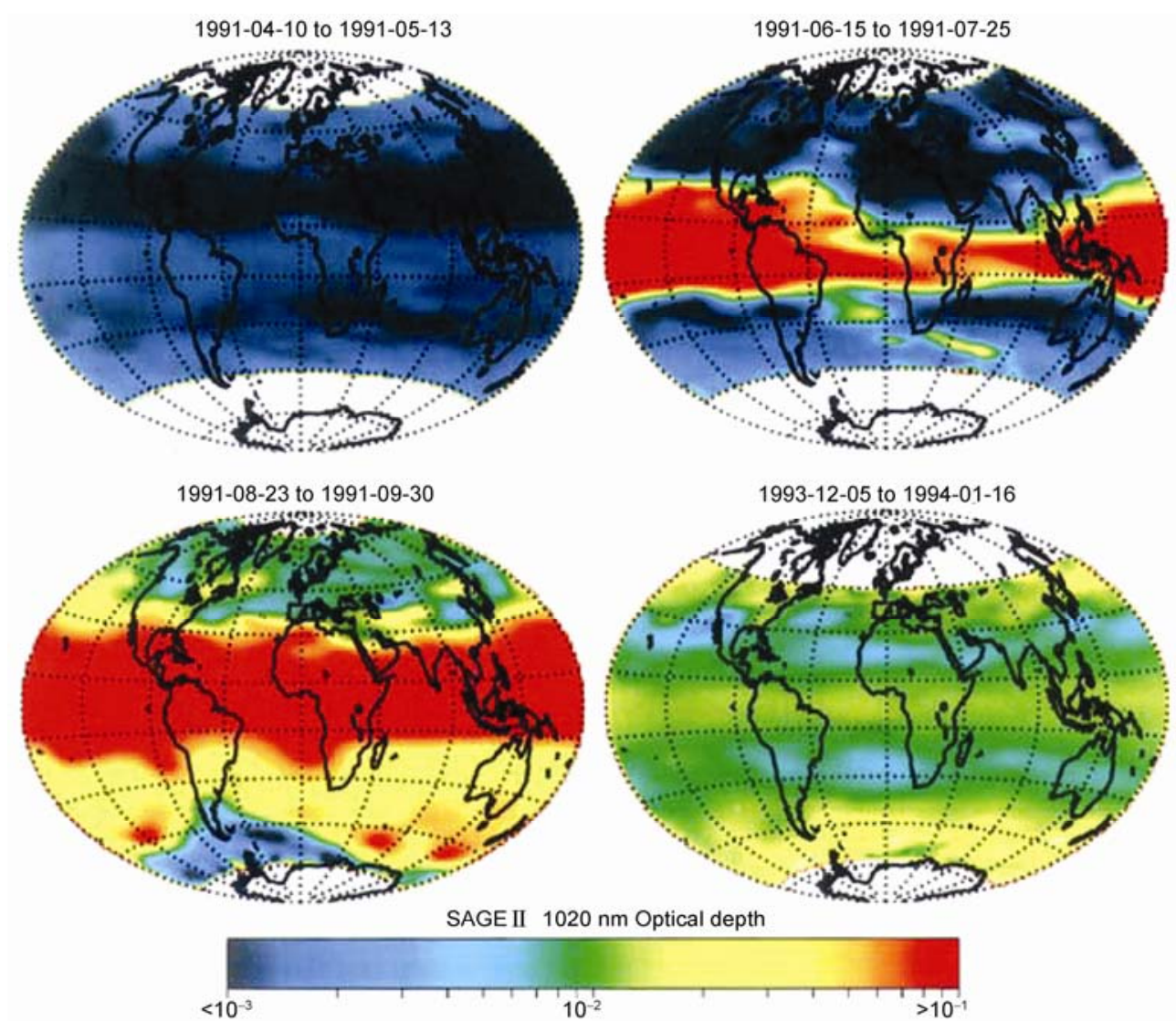

Figure 5 Integrated SAGE II stratospheric optical depth at a wavelength $1020 \mathrm{~nm}$ for four periods just preceding and following the eruption of Mount Pinatubo [24].

aerosols erupted by Pinatubo caused great impacts not only on the global radiation balance, but also on stratospheric chemical processes, especially stratospheric ozone, which plays an important role in the stratospheric radiation balance.

\subsection{Influences of chemical processes of Pinatubo vol- canic ash on ozone depletion}

Stratospheric ozone may influence stratospheric atmospheric circulation and temperature stratification through heating from the absorption of ultraviolet radiation and parts of infrared radiation. This process plays a dominant role in the stratospheric radiation balance [25]. As has been noted, ozone had decreased on decadal time scales since 1992 (Figure 4(c) and (d)), which does not correspond to the amount before the Pinatubo eruption along with retrieval of the stratospheric visible depths in the subsequent $2-3$ a. To understand the chemical processes of ozone decadal depletion, it is important to identify the following three mechanisms.

First, through observational data analysis, Johnston et al. [11] and Koike et al. [12] found that stratospheric $\mathrm{NO}_{2}$ had reduced by $40 \%$, and that $\mathrm{HNO}_{3}$ concentrations had increased [13]. These findings suggest that reactive nitrogen species (e.g. $\mathrm{NO}_{2}$ ) were repartitioned into less reactive forms (e.g. $\mathrm{HNO}_{3}$ ) which, in turn, helped to temporarily enhance the levels of active, ozone-depleting chlorine radicals (e.g. $\mathrm{ClO}$ ) relative to those of more inert chlorine reservoirs (e.g. $\mathrm{HCl}$ ). Stratospheric ozone was reduced by the reaction chain caused by $\mathrm{Cl}$ atoms and $\mathrm{ClO}_{x}$ free radicals $[26,27]$, and were greatly depleted by the 3 megatons of $\mathrm{Cl}$ species erupted by Pinatubo [28].

Second, there were about 17 megatons of $\mathrm{SO}_{2}$ erupted into the stratosphere. Bluth et al. [29] and McCormick et al. [30] showed that $\mathrm{SO}_{2}$ changed to gaseous $\mathrm{H}_{2} \mathrm{SO}_{4}$ after several weeks, when $\mathrm{SO}_{2}$ had been transported into the stratosphere. Furthermore, gaseous $\mathrm{H}_{2} \mathrm{SO}_{4}$ was concentrated into tiny crystals by dualistic homogeneous crystals. Thus, sulfate crystal aerosols could make the $\mathrm{ClO}$ active $[31,32]$. The ozone was decreased by the chain produced by the $\mathrm{Cl}$ atoms and $\mathrm{ClO}_{x}$ free radicals [24].

Third, abundant $\mathrm{H}_{2} \mathrm{O}$ and $\mathrm{CH}_{4}$ were erupted into the stratosphere. As a consequence, $\mathrm{H}_{2} \mathrm{O}$ could photolyze into $\mathrm{H}_{2}$ and $\mathrm{HO}$ in the stratosphere. In the presence of $\mathrm{H}_{2} \mathrm{O}, \mathrm{H}_{2}$ and $\mathrm{CH}_{4}$, stratospheric ozone could be depleted by the reaction between the $\mathrm{HO}_{x}$ free radicals and the ozone [33]. The precondition of the reaction between $\mathrm{HO}_{x}$ free radicals and the ozone had been satisfied after the Pinatubo eruption. Thus, the mechanism of ozone depletion induced by the $\mathrm{HO}_{x}$ free radicals may have taken place in the stratosphere after the Pinatubo eruption. However, this mechanism needs 
further confirmation through numerical simulation.

The first and second mechanisms of ozone depletion have been illustrated by the observational data and the third mechanism may have played out after the Pinatubo eruption. Thus, chemical processes of the stratospheric aerosols erupted by Pinatubo induced the stratospheric ozone decadal depletion.

\subsection{Influence of ozone decadal depletion on stratospher- ic tropical decadal cooling}

Figure 6 shows the regressed annual averaged 30-hPa air temperature, based on the January total column ozone. It can be seen that the regressive functions are significant, exceeding the $95 \%$ confidence level over the tropics and subtropics. Regressed 30-hPa air temperature of 2006 is $1.2-1.4^{\circ} \mathrm{C}$ lower than that in 1979 . The correlation coefficients between annual $30-\mathrm{hPa}$ air temperature and the regressed time series exceed 0.7 over the tropics and 0.8 over the middle Pacific. This means that the variation of ozone could explain about $50 \%$ of the variance over the tropics and $64 \%$ of the variance over the middle Pacific. Hence, the ozone variation could explain well the variation in the stratospheric air temperatures.

As has been noted, the DDACs of the July and January total column ozone occurred in 1991 and 1992, respectively. The DDACs of $30-\mathrm{hPa}$ air temperature occurred over the tropics in 1992, over the subtropics in 1993 and over the mid-latitudes in 1994-1995. DDACs of total column ozone took place earlier than those of the stratospheric air temperature. It is well known that stratospheric ozone may strongly influence stratospheric temperature stratification and atmospheric circulation through heating from absorption of ultraviolet radiation and parts of infrared radiation. Thus, stratospheric ozone may be a crucial component in the stratospheric radiation balance. In addition, ozone variation could explain well patterns in the stratospheric air temperature during the past three decades. Thus, the DDACs of stratospheric air temperature may be attributed to processes occurring in the stratospheric ozone.

\subsection{Mechanism of stratospheric DDACs in the early 1990s induced by the Pinatubo eruption and historical verifications}

According to the aforementioned analyses, the possible mechanism for the stratospheric DDACs in the early 1990s is described here (Figure 7). The Pinatubo eruption injected substantial amounts of volcanic ash into the stratosphere, which induced a series of chemical reactions there. Stratospheric ozone was depleted by the effects of nitrate and sulfate activities on the $\mathrm{ClO}$ and $\mathrm{HO}_{\mathrm{x}}$ free radical reaction chain (Figure 7). As a result, the DDACs of stratospheric ozone occurred in 1991-1992. Following the decadal decrease of ozone, the heat absorbed by the ozone also decreased in the following decades in the stratosphere. Accordingly, the DDACs of stratospheric air temperature occurred in the early 1990s. Thus, the DDACs of stratospheric air temperature in the early 1990s may have been induced by the Pinatubo eruption. This also means that one strong volcanic eruption could induce the decadal variation of the stratospheric climate.

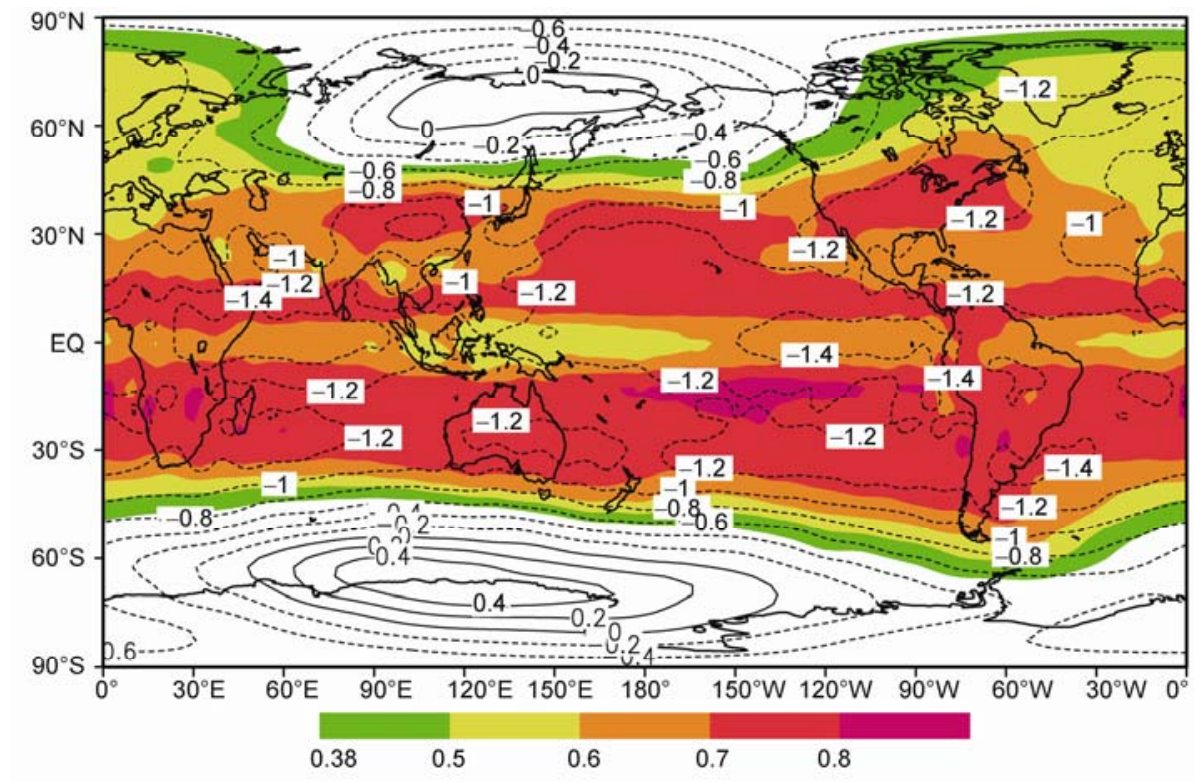

Figure 6 Regressed annual $30-\mathrm{hPa}$ air temperature based on the January total column ozone over $\left(40^{\circ} \mathrm{E}-120^{\circ} \mathrm{W}, 80^{\circ}-10^{\circ} \mathrm{S}\right)$. The color shading (correlation coefficient between annual $30-\mathrm{hPa}$ air temperature and the regressed time series) is significant at the $95 \%$ confidence level. The contours represent the differences between the 30-hPa air temperature of 2006 and that of 1979. 


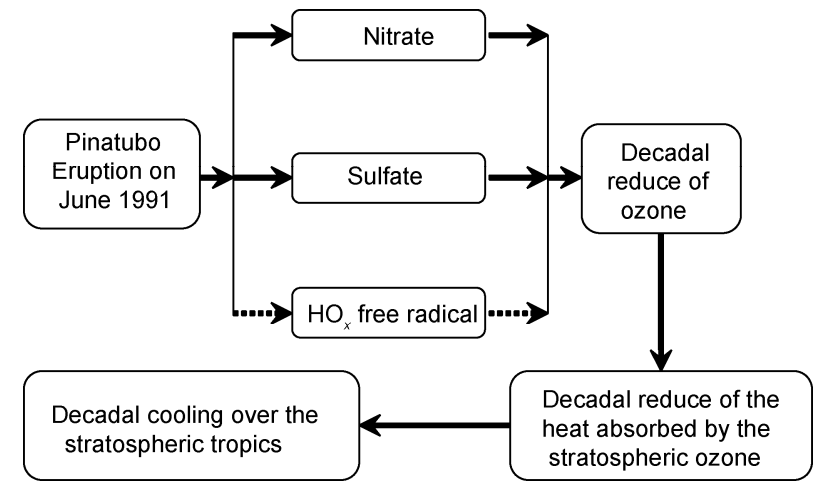

Figure 7 Schematic chart showing the possible mechanism of stratospheric decadal cooling in the early 1990s. The dashed arrowhead indicates the possible existence of chemical processes.

In addition, stratospheric decadal cooling existed not only after the Pinatubo eruption, but also following another two tropical volcanic eruptions. In the modern observational data period, there have been three strong volcanic eruptions. They are the Pinatubo eruption in the Philippines in June of 1991, the El Chichon eruption in Mexico in April of 1982, and the Agung eruption in Indonesia in March of 1963. Their VEIs were 6th, 5th and 4th levels, respectively [3]. It can be seen from Figure 4(b) and (c) that the DDACs of the January total column ozone and $30-\mathrm{hPa}$ tropical air temperature both happened in 1983 and 1992. These facts suggest that the decadal depletion of ozone and stratospheric decadal cooling coincided after the El Chichon and Pinatubo eruptions. There are no observational ozone data for the Agung eruption in 1963. The DDACs of 30-hPa tropical geopotential height and air temperature happened in 1964 and 1966, respectively. Both of these occurred after the Agung eruption. Thus, the conditions of the decadal decrease of stratospheric ozone and air temperature after the El Chichon eruptions are in agreement with conditions of Pinatubo. The phenomenon of stratospheric decadal cooling after the Agung eruption also is consistent with the above conclusions.

\section{Discussion and conclusions}

This study has identified that the DDACs of stratospheric air temperature took place in the early 1990s. Furthermore, this study has described the relationship between the Pinatubo eruption and decadal decreases in stratospheric ozone and air temperatures. Based on these analyses the following conclusions are made. The Pinatubo volcano erupted on 12-16 June, 1991. The chemical processes occurring within stratospheric volcanic ash induced the DDACs of total column ozone in 1991-1992 via ozone's reactions with ozone's $\mathrm{ClO}$ radicals actived by nitrate and sulfate and HO free radicals. Moreover, the absorbed heat by stratospheric ozone decreased on a decadal time scale.
As a result, the DDACs of stratospheric air temperature occurred in the early 1990s. Thus, the DDACs of stratospheric air temperature may be attributed to the Pinatubo eruption. This result also indicates that one strong volcanic eruption could induce stratospheric decadal climate variation.

One strong volcanic eruption can induce stratospheric warming after about 2-4 months and tropospheric cooling after about 10 months. Stratospheric and tropospheric air temperatures appear to recover a few years after the eruption. The continuing effects of many volcanic eruptions could cause decadal to hundred and even thousand-year time scale trends in climate. This study suggests that one strong volcanic eruption could induce decadal cooling of the stratospheric climate. Thus, one strong volcanic eruption could influence not only seasonal and inter-annual climate variability, but also stratospheric decadal climate variability.

So far, chemical and optical processes of volcanic eruption are incarnated in General Chemical and General Climate Models, mainly via the application of visible depth variations. However, such a scheme does not reflect the actual reaction of the optical and chemical processes occurring in association with the volcanic ash. The conditions of the Pinatubo eruption in 1991 already have been detected by satellite images. The future challenge will be to add the optical and chemical process of volcanic ash into the present General Chemical Model and General Climate Model. Moreover, further studies are needed to simulate stratospheric warming about 2-4 months after, and tropospheric cooling about 10 months after a strong eruption, in relation to a decadal decrease of ozone and stratospheric decadal cooling.

We thank three anonymous reviewers for their helpful comments and Prof. Liu Yu for helpful discussions. This work was supported by the National Basic Research Program of China (2010CB950400) and the National Natural Science Foundation of China (40890050 and 40528006).

1 Li X D, Wang S W, Liu R X. Advances in volcano-climatology (in Chinese). Seismol Geomagn Observ Res, 1996, 17: 73-80

2 Qu W Z, Huang F, Zhao J P, et al. The influence of volcanic activities on the abnormal changes of climate in stratosphere of the northern hemisphere (in Chinese). Prog Geophys, 2006, 21: 650-659

3 Qu W Z, Bai Y, Huang F, et al. Effect of volcanic activity on the temperature in the tropical upper atmosphere (in Chinese). Chin $\mathbf{J}$ Geophys, 2006, 49: 1308-1315

4 Newhall C G, Self S. The volcanic explosivity index (VEI): An estimate of explosive magnitude for historical volcanism. J Geophys Res, 1983, 87: 1231-1238

5 Gerlach T M, Westrich H R, Symonds R B. Preeruption vapor in magma of the climactic Mount Pinatubo eruption: Source of the giant stratospheric sulfur dioxide cloud. In: Newhall C G, Punongbayan R S, eds. Fire and Mud: Eruptions and lahars of Mt. Pinatubo, Philippines. Quezon City and Seattle: Philippine Institute of Volcanology and Seismology and University of Washington Press, 1998. 44-81

6 Chen H B, Lü D R, Xu L S. Variation characteristics of stratospheric aerosols due to the Pinatubo eruption by SAGE II data. Chinese Sci Bull, 1994, 39: 231-234

7 Dai J C, Mosley-Thompson E, Qin D H. Evidence of the $1991 \mathrm{Pi}-$ 
natubo volcanic eruption in South Polar snow. Chinese Sci Bull, 1999, 44: 756-760

8 Yang Q L, Qiu J H, Zhao Y L. Effects of volcanic aerosol on ozone change trends over Beijing (in Chinese). J Atmos Sci, 1998, 22: 686-692

9 Wu B Y, Lü D R. Stratospheric aerosols variation monitored by the polarization of skylight after the Pinatubo eruption (in Chinese). Prog Nat Sci, 1995, 5: 222-224

10 Qiu J H, Pan J D, Yang Q L, et al. Variation of atmospheric aerosols over 10 sites in China during 1980-1994 (in Chinese). J Atmos Sci, 1997, 21: 725-733

11 Johnston P V, McKenzie R L, Keys J G, et al. Observations of depleted stratospheric $\mathrm{NO}_{2}$ following the Pinatubo volcanic eruption. Geophys Res Lett, 1992, 19: 211-213

12 Koike M, Jones N B, Matthews W A, et al. Impact of Pinatubo aerosols on the partitioning between $\mathrm{NO}_{2}$ and $\mathrm{HNO}_{3}$. Geophys Res Lett, 1994, 21: 597-600

13 Rinsland C P, Gunson M R, Abrams M C, et al. Heterogeneous conversion of $\mathrm{N} 2 \mathrm{O} 5$ to $\mathrm{HNO}_{3}$ in the post-Mount Pinatubo eruption stratosphere. J Geophys Res, 1994, 99: 8213-8219

14 Hofmann D J, Oltmans S J, Larhrop J A, et al. Ozone loss in the lower stratosphere over the United States in 1992-1993: Evidence for heterogeneous chemistry on the Pinatubo aerosol. Geophys Res Lett, 1994, 21: 65-68

15 Komhyr W D, Grass R D, Evans R D, et al. Unprecedented 1993 ozone decrease over the United States from Dobson spectrophotometer observations. Geophys Res Lett, 1994, 21: 201-204

16 Dlugokencky E J, Steele L P, Lang P M, et al. The growth rate and distribution of atmospheric methane. J Geophys Res, 1994, 99: 17021-17043

17 Etheridge D M, Steele L P, Langenfelds R L, et al. Natural and anthropogenic changes in atmospheric $\mathrm{CO}_{2}$ over the last 1000 years from air in Antarctic ice and firn. J Geophys Res, 1996, 101: 4115-4128

18 Kalnay E M, Coauthors. The NCEP/NCAR reanalysis project. Bull Amer Meteor Soc, 1996, 77: 437-471

19 Martinson D G. Introduction. In: Martinson D G, Bryan K, Ghil M, et al., eds. Natural Climate Variability on Decade-to-Century Time Series. Washington: National Academy Press, 1995. 5-8

20 Li J P, Chou J F, Shi J E. Complete definition and types of abrupt climatic change (in Chinese). J Beijing Meteorol College, 1996, 1: 7-12

21 Xiao D, Li J P. Main decadal abrupt changes and decadal modes in global sea surface temperature field (in Chinese). J Atmos Sci, 2007, 31: 839-854

22 Feng G L, Dong W J, Gong Z Q, et al. Theory and Method of Nonlinear Spatio-temporal Distribution of Observational Data (in Chinese). Beijing: Meteorological Press, 2006. 1-227

23 Xiao D, Li J P. Spatial and temporal characteristics of the decadal abrupt changes of atmosphere-ocean system in 1970s. J Geophys Res, 2007, 112: D24S22, doi:10.1029/2007JD008956

24 Self S, Zhao J X, Holasek R E, et al. The atmospheric impact of the 1991 Mount Pinatubo eruption. In: Newhall C G, Punongbayan R S, eds. Fire and Mud: Eruptions and Lahars of Mt. Pinatubo. Philippines, Quezon City and Seattle: Philippine Institute of Volcanology and Seismology and University of Washington Press, 1998. 1-43

25 Baede A P M. Glossary. In: Solomon S, QineManning M, et al., eds. Climate Change 2007: The Physical Science Basis. Contribution of Working Group I to the Fourth Assessment Report of the Intergovernmental Panel on Climate Change. Cambridge and New York: Cambridge University Press, 2007. 950

26 Molina M J. Polar ozone depletion. Angew Chem Int Ed Engl, 1996, 35: $1778-1785$

27 Rowland F S. Stratospheric ozone depletion. Angew Chem Int Ed Engl, 1996, 35: 1786-1798

28 Martinson D G. Mechanisms and Predictability. In: Martinson D G, Battisti D S, Bradley R S, et al., eds. Decade-to-century-scale Climate Variability and Change: A Science Strategy. Washington: National Academy Press, 1998. 1-5

29 Bluth G J S, Doiron S D, Schnetzler C C, et al. Global tracking of the SO2 clouds from the June, 1991 Mount Pinatubo eruptions. Geophys Res Lett, 1992, 19: 151-154

30 McCormick M P, Thomason L W, Trepte C R. Atmospheric effects of the Mt Pinatubo eruption. Nature, 1995, 373: 399-404

31 Borrmann S, Solomon S, Dye J E, et al. Heterogeneous reactions on stratospheric background aerosols, volcanic sulfuric acid droplets, and type I polar stratospheric clouds: Effects of temperature fluctuations and differences in particle phase. J Geophys Res, 1997, 102: 3639-3648

32 Bregman B, Wang P H, Lelieveld J. Chemical ozone loss in the tropopause region on subvisible ice clouds, calculated with a chemistry-transport model. J Geophys Res, 2002, 107: 4032

33 Wang Z, Li H, Zhou S. Review on chemical study of stratospheric ozone depletion. Chinese Sci Bull, 2001, 46: 619-625

Open Access This article is distributed under the terms of the Creative Commons Attribution License which permits any use, distribution, and reproduction in any medium, provided the original author(s) and source are credited. 